\title{
Los vagos de la ciudad de México y el Tribunal de Vagos en la primera mitad del siglo $\mathrm{XIX}^{*}$
}

Sonia Pérez Toledo

UAM-I

$\mathrm{L}$

a sociedad urbana de México -como la de otras ciudades del antiguo régimen-, se caracterizó por una pronunciada diversidad interna asi como por una notable y compleja jerarquización social con grandes contrastes de riqueza y pobre$\mathrm{za}^{1}{ }^{1}$ contrastes de los que dejaron testimonio los viajeros de la época. Al me-

* Una primera versión de este trabajo fue presentada en el seminario "Gobierno y política en las ciudades mexicanas, 1808-191." , México, Instituto de Investigaciones Dr. José María Luis Mora, 18-19 de septiembre de 1991.

1 para una descripción de los diferentes sectores urbanos franceses vease, Sewell, Work, 1987, pp. 18-19. nos desde la segunda mitad del siglo XVIn las autoridades coloniales mostraron gran preocupación por el aumento de la "ociosidad de la plebe" que, como señalara Bernard Ward al promediar dicho siglo, respondía a la falta de empleo estable y a la incapacidad del sistema económico para asimilar a los hombres desempleados, ${ }^{2}$ que eran vistos como "vagos e indigentes".

A partir de este periodo y hasta mediados del siglo XIX, la abundancia de disposiciones legislativas muestran que las autoridades, coloniales primero y republicanas después, empren-

2 Martin, "Pobres", 1985, p. 104. 
dieron con mayor vigor una campaña contra la vagancia. ${ }^{3} \mathrm{La}$ legislación de la época en torno a ésta tenía como objetivos disminuir el número de "vagos", evitar su proliferación, convertirlos en hombres útiles a la sociedad y, finalmente, separarlos de la población "decente".

En la ciudad de México, durante los últimos años del siglo xvir y las primeras décadas del XIX, la persecución de los vagos estuvo estrechamente vinculada al control de inmigrantes (cuyo flujo se incrementó por la crisis rural y el inicio del movimiento de Hidalgo), a la disminución de la inestabilidad social y al reclutamiento militar. ${ }^{4}$

En el periodo transcurrido entre la real orden de 1745 y el bando de 1845 (ambas sobre vagos), la legislación en la materia suftió algunas modificaciones. Los cambios se dieron sobre todo en cuanto a la concepción de la mendicidad. No obstante, permanecieron constantes en ella la definición de la vagancia y las medidas para su corrección, aunque con el paso del tiempo fue convirtiéndose en una regulación que, además de incluir a otras clases de pobres, para las cuales la ciudad de México no ofrecía oportunidades de empleo, ${ }^{5}$ involucró cada vez más a los miembros del ayuntamiento en la persecución de los llamados vagos.

${ }^{3}$ Arrom, "Vagos", 1988, pp. 71-87.

4 Van Young, "Islands", 1988, p. 151; véase tambien Van Young, The ricb, 1987, pp. 1-12 y 38-42.

5 Véase Di Tella, "Las clases", 1979, pp. 481.524; Moreno, "Los trabnjadores", 1981, pp. 327-330; Silvia Arrom señala que la lista de compartimientos prohibidos aumentó de 16 a 21 entre los años 1745 y 1845, Arrom, "Vagos", 1988 , p. 76.
IA LEGISIACIÓN CONTRA IA VAGANCIA Y EL. AYUNTAMIENTO

En el mes de abril de 1821, las autoridades del Ayuntamiento de la ciudad de México fueron informadas de que, por decreto de las Cortes (1820), seguian en vigor las disposiciones contra vagos de 1745. De acuerdo con el artículo primero se estipuló que los jefes políticos, alcaldes y ayuntamientos debían vigilar a los individuos que no tuvieran empleo, oficio o modo de vivir conocido, de tal suerte que "los antes llamados gitanos, vagantes o sin ocupación útil; los demás vagos, holgazanes y mal entretenidos calificados en la real orden de 30 de abril de $1745[\ldots]$ serán perseguidos y presos, previa la información sumaria". 6 Más tarde, en 1827, se indicó que era obligación de los alcaldes y auxiliares de cuartel de la ciudad, cuidar que no hubiera "vagos" ni "hombres mal entretenidos" en el cuartel a su cargo. ${ }^{7}$ En ese mismo año el gobierno del Distrito Federal dispuso que se procediera a detener a los "vagos y mal entretenidos" y que la milicia del Distrito debería apre. hender a

todos aquellos individuos que carezcan de oficio u otra ocupación honesta que provea su subsistencia o que aun cuando sepan algunas artes $y$ oficios no lo ejerciten y pasen el tiempo en

6 Archivo Histórico de la Ciudad de México (en adelante sHCM), Vagos, vol. 4151(1), exp. 2.

${ }^{7}$ Artículo $8^{\circ}$ de la "Cartilla aprobada por el Ayuntamiento de México, para los alcaldes, auxiliares $y$ ayudantes de cuartel", agosto 31 de 1827, en Dublán y Lozano, Legislacion, 1876, vol. u, pp. 15-16. 
casas de juego, pulquerías, billares y otros lugares. ${ }^{8}$

Estos individuos pasarían a formar parte de la milicia permanente en calidad de remplazos.

Durante todo el año de 1827 , abundaron las disposiciones contra vagos en el ayuntamiento. Por orden del gobierno del Distrito, se le pidió al alcalde de primera nominación que dispusiera que los individuos de la corporación procedieran a detener a los vagos; para la calificación de las personas aprehendidas, una comisión de cuatro miembros del propio ayuntamiento debía reunirse todos los días por la mañana. Se recomendaba a la comisión actuar con imparcialidad y circunspección

al graduar quiénes son vagos o no para que este gobierno proceda a remplazar el ejército sin necesidad de armncar a la agricultura y artes ciudadanos honrados y útiles, libertando al mismo tiempo a esta populosa capital y demás lugares del Distrito de hombres que siendo en la vía mal entretenidos y ociosos pasarían a ser mañana criminales. ${ }^{9}$

E1 3 de marzo de 1828 se decretó el establecimiento de tribunales especiales para la calificación de los vagos en el Distrito y Territorios, para el día 11 el Tribunal de Vagos de la ciudad de México ya había sido instalado y ejercía sus funciones. ${ }^{10}$ En el decreto que dio

${ }^{8}$ AHCM, Vagos, vol. 4151, exp. 4 (las cursivas son mías).

9 "Orden dada el 26 de febrero de 1827", AHCM, Vagos, vol. 4151, exp. 4.

${ }^{10}$ AHCM, Vagos, vol. 4151, exp. 6. vida a este tribunal se señalaba como "vagos y viciosos" a todas aquellas personas

I. [...] que sin oficio ni beneficio, hacienda o renta viven sin saber de qué les venga la subsistencia por medios lícitos y honestos. II. El que teniendo algún patrimonio o emolumento o siendo hijo de familia no se le conoce otro empleo que el de las casas de juego, compañías mal opinadas, frecuencias de parajes sospechosos y ninguna demostración de emprender destino en su esfera, III. El que vigoroso, sano y robusto en edad y aun con lesión que no le impida ejercer algún oficio, sólo se mantiene de pedir limosna. [y] IV. El hijo de familia que mal inclinado no sirve en casa y en el pueblo de otra cosa que escandalizar con la poca reverencia u obediencia a sus padres, y con el ejercicio de las malas costumbres, sin propensión o aplicación a la carrera que le ponen. ${ }^{11}$

Desde la creación del Tribunal de Vagos en 1828 -y hasta 1850 , periodo del que me ocupo en este trabajo-, fue constante la participación de los funcionarios del ayuntamiento no sólo en la persecución de los llamados "vagos", sino también en los juicios. Los alcaldes y auxiliares de cuartel jugaron un papel importante, $y$ muchas veces de ellos dependió la detención de una persona, o bien que la sentencia fuera o no favorable al acusado. Por una parte, tenían la obligación de vigilar que en las zonas a su cuidado no hubiese "vagos y viciosos", pero, por la otra, en algunas ocasiones antepu-

11 Dublán y Lozano, Legislación, 1876, vol. II, pp. 61-63. 
sieron intereses o relaciones personales a esa obligación. Así lo señaló Isidro Olvera, encargado de los cuarteles menores 15 y 16 , cuando sus auxiliares le informaron que en esos cuarteles no se había encontrado a vagos que remitir. Por lo que Olvera indicó en su informe que

sólo el que no haya vivido en México podría creer, que en la mayor parte de los bartios de Santa Ana y el Carmen no se encontrara un vago, èy qué remedio para hallar la verdad en un asunto tan delicado y de tanta complicación? [...] Yo conociendo lo odioso de un espionaje $y$ lo ilegal de un cateo inquisitorial quise que mis auxiliares para desempeñar las superiores órdenes del gobierno copiaran el artículo 6o de la ley, [...] sin embargo nada se ha conseguido con este arbitrio. De mis tres auxiliares uno tiene un café y el otro una vinatería, $y$ así de éstos no se puede esperar que denuncien a los que contribuyen para su subsistencia. ${ }^{12}$

Por otra parte, algunos de estos funcionarios estaban conscientes de que muchas de las personas acusadas de vagancia, no eran otra cosa sino individuos que carecian de empleo a pesar de que tenían algún oficio. Como se puede apreciar en el informe del encargado de estos cuarteles, éste indicó que había "pocas manufacturas en que pueden ocuparse nuestros artesanos", lo que daba como resultado que

12 "Oficio de Isidro Olvera del 29 de abril de 1828", АHCM, Vagos, vol. 4151, exp. 5. sí se logran hombres que siendo tejedores, plateros, etcéter, y dicen que no trabajan porque no los ocupan, [mientras] que hay tanto jugador público a quienes no se incomoda; [esto] es un conflicto inexplicable. ${ }^{13}$

A dos años de haberse establecido el Tribunal de Vagos, el gobierno del Distrito hizo saber a los alcaldes auxiliares, por medio de una circular, que tenían la obligación de presentar semanariamente ante el tribunal correspondiente a cuatro vagos. La circular de 1830 decía que la capital se encontraba "inundada de vagos, que por todos aspectos son perjudtciales al público" y que era obligación de los alcaldes auxiliares

tener conocimiento de la clase de gente que vive en sus respectivos cuarteles, y de su modo de vivir, observando a la vez la conducta de algunos individuos que se hacen sospechosos por su ociosidad. ${ }^{14}$

En 1833 se pretendió aumentar el número de alcaldes auxiliares para tener un mayor control sobre la población y, desde luego, para evitar la proliferación de la "vagancia". Incluso se pensó en el nombramiento de auxiliares para cada una de las manzanas. ${ }^{15}$

Un año después, se dictaron disposiciones para el levantamiento de un padrón destinado a las elecciones de diputados. En ellas se establecie.

\footnotetext{
13 Ibid., las cursivas son mías.

14 Aнсм, Vagos, vol. 4151, exp. 19 las cursivas son mías.

15 AHCM, Vagos, vol. 1154 , exp. 146.
} 
ron prevenciones en contra de los vagos; se pretendía que, al efectuarse el empadronamiento general, todos los que resultaran sin oficio ni ocupación fueran presentados ante el Tribunal de Vagos. Asimismo, se buscó la mejor manera para determinar el estado de vagancia de los detenidos. De esta suerte, quedó asentado que:

El síndico $[\ldots]$ tendrá muy presente cuanto sea conducente a depurar la verdad y a impedir que los vagos, que son el semillero fecundo de tantos crínenes, continúen mezclados con la sociedad, con los artesanos, comerciantes y demás individuos que la sostienen con su trabajo y su industria. ${ }^{16}$

Una forma para asegurar la separación de la población "decente", "trabajadora" e "industriosa" de los indeseados "vagos y viciosos", fue indicada en los siguientes artículos:

12. Los maestros serán responsables de ha conducta de sus oficiales y aprendices mientras duren en sus talleres y para admitirlos les exigirá una constancia de buen porte, seguridad y honradez, del maestro en cuyo taller hubiere antes trabajado el oficial $o$ aprendiz que nuevamente contrate. [y]

13. Si antes no hubiere estado en otro taller, las segutidades que debe tener quedan a discreción del maestro,

16 Vease "Decreto del 8 de agosto de 1834 ", en Dublín y Lozano, Legislacionn; 1876 vol. $n$, p. 716; y la Disposición del Gobierno del Distrito sobre "Vagos o Empadronamiento General del año de 1834", firmada por José María Tornel el 11 de agosto del mismo año. AHCM, Vagos, vol. 4154, exp. 148. entendido de la responsabilidad que contrae. ${ }^{17}$

A partir de este año, una gran parte de los artesanos que comparecieron ante el Tribunal de Vagos fueron $a b-$ sueltos, pero quedaban bajo la custodia de un maestro con taller público al que se le encomendaba la enseñanza del oficio y el cuidado de su conducta. Esta obligación la adquiria el maestro mediante la firma de una cartacompromiso que aparece al final de las sumarias. ${ }^{18}$

La legislación contra la vagancia condenaba tanto la falta de dedicación al trabajo como el vicio. Por lo mismo, durante todo este periodo fue muy común que las personas desempleadas o con empleos temporales lle. garan al tribunal acusadas de vagancia. Este doble sentido de la legislación explica también que, como es fácil suponer, cualquier individuo que se encontraba en pulquerías o vinaterías fuera de las horas permitidas o en horarios considerados de trabajo, fuera considerado vago; más aún, si su vestido y comportamiento resul. taban "sospechosos". ${ }^{19}$ Sin embargo,

17 AHCM, Vagos, vol. 4154, exp. 148

18 Tal es el caso de José María Cordero, sastre de 16 anos, que se inicio en el aprendizaje del oficio a los 14; este fue entregado al maestro Andrés Hernández para que trabajara en su taller público. Lo mismo sucedio al oficial de curtidor Pablo Camacho, que a los 22 años fue entregado a un maestro de su oficio, que era propietario del taller público de curtiduría ubicado en el Puente de Santo Tomás. Véase "Contra Pablo Camacho" y "Contra Jose María Cordero", septiembre y octubre de 1835 , AllCM, Vagos, vol. 4154, exps. 160 y 163.

19 Tal fue el caso del tejedor Margarito Barrera que en 1845 se le siguió causa por vago. 
muchas de las personas aprehendidas eran liberadas o absueltas, pues una vez que se realizaban las averiguaciones, y en el momento del juicio, no faltaban los testimonios que llevaban al Tribunal de Vagos a dictar una sentencia favorable para los acusados. Lo que bien puede indicar la existencia de un clima de tolerancia por parte del tribunal e incluso entre los miembros del ayuntamiento hacia los desempleados, que no hacia los vagos, como se podrá ver en seguida.

En cuanto a que la legislación contra vagancia y la actividad de Tribunal de vagos no se traducía en la disminución del número de vagos en la ciu. dad, en 1841 el gobernador del Departamento de México pidió informes al ayuntamiento y a los encargados del Hospicio de Pobres y de la Casa de las Recogiclas para saber si estos establecimientos podían albergar a todas aquellas personas que constituían -según las propias palabras del presidente de México- uno de los mayores problemas y causas de la decadencia de la policía de la capital, esto es

el sinnúmero de mendigos que transitan por las calles, ocupando las banquetas por las noches y molestando al público $[\ldots y$ y a la multitud de mujeres ebrias y escandalosas que ofenden al público con su indecente desnudez y lastiman los oídos con sus obscenas palabras. ${ }^{20}$

Barrera fue detenido por encontrarse en una pulquería "en horas de taller". AHCM, Vagos, vol. 4156, exp. 280.

20 "Disposición del gobernador del Departamento de México, octubre 29 de 1841 ", Archivo General de la Nación (en adelante AGN), Gobernación, legajo 130 , caja 1 , exp. 5 .
Por toda respuesta, el gobierno fue informado de que el hospicio carecía de los fondos suficientes para recibir a todos los individuos que fueran detenidos, en tanto que el edificio que originalmente era para la Casa de las Recogidas había sido destinado para otros fines desde 1829. Por su parte, el ayuntamiento informó que la corporación municipal había trabajado en cumplimiento de la ley sobre vagos prestándose gustosa a colaborar con las autoridades, estableciendo para ello una Junta Calificadora de vagos que había funcionado prácticamente sin interrupción clesde el mes de mayo de 1837. La misma junta, según el informe, había hecho repetidas advertencias a los capitulares y auxiliares de cuartel para que cuidaran de no inferir violencia sobre los hombres útiles y ocupados sino sobre aquellos verdaderamente vagos.

En pocas palabras [concluía el informe], el ayuntamiento ha tentado cuantas medidas están a su alcance para desterme de esta capital el detestable vicio de la vagancia e inspirar al vecindario el amor al trabajo, a la instruccion y a las buenas costumbres. ${ }^{21}$

Un poco más tarde, el 3 de febrero de 1845, se emitió el decreto que estableció un tribunal para juzgar a los vagos en todas las cabeceras de partido del Departamento (articulo $\left.1^{\circ}\right)$. Dichos tribunales se formarían

21 "Informe del Ayuntamiento al gobernador del Departamento de México", noviembre 6 de 1841, AGN, Gobernación, legajo 130, caja 1 exp. 5 (las cursivas son mías). 
con uno de los regidores del ayuntamiento, "síndico del mismo cuerpo", y tres vecinos del lugar nombrados por la corporación el primer mes de cada año (artículo $2^{\circ}$ ). Las personas calificadas de "vagos" se remitirian al prefecto de distrito y se liberaría a los que no lo fueran (artículo $8^{\circ}$ ). ${ }^{22}$ De acuerdo con esta ley, la mendicidad en cualquiera de sus formas quedó prohibida. Esto revela un cambio importante en cuanto a la concepción de la caridad al promediar el siglo XIX; en otras palabras, la prohibición de la mendicidad indica el avance del proceso de secularización en la sociedad de la época, que ya no concibe a la caridad (tradicional valor católico) como un deber de los ricos y un derecho de los pobres. También se prohibieron los juegos de naipes, rayuela e incluso el dedicarse a tocar instrumentos (como la vihuela) en tabernas o pulquerías. Como es lógico, se reiteró la condena al ocio y la falta de dedicación al trabajo. ${ }^{23}$

En este decreto se indicó también que aquellos que tuvieran más de $\mathbf{1 8}$ años y fueran señalados como vagos serían destinados al servicio de las armas de ser aptos para ello; de no serlo, pasarían a las fábricas de hilados y tejidos, ferreterías o labores de campo, y en el caso de que existiera alguna dificultad, pasarían a algún obraje o establecimiento en el que se mantuvieran ocupados y seguros. De la misma manera, se indicó que los menores serían destinados al aprendizaje de

22 "Decreto del 3 de febrero de 1845", АHCM, Vagos, vol. 4778, exp. 303.

23 Ibid. un "oficio a un taller de zapatería, sastrería, herrería, u otro de igual clase en que quieran recibirlos, cuidando de que no se fuguen"; quedaba asentado que si había alguna dificultad para colocarlos en algún taller, pasarían a los hospicios o casas de correción. ${ }^{24}$

Como es fácil observar, la lista de actividades o comportamientos prohibidos aumentó significativamente con la ley de 1845 , si la comparamos con la establecida cien años antes. listo in. dica la poca eficacia de la legislación contra la vagancia en cuanto que, en la práctica, no daba los resultaclos esperados. Los testimonios de contemporáneos a la época son a todas luces reveladores; basta recordar el terror con que Francis Calderón de la Barca describió a los vagabundos y mendigos de la ciudad de México. ${ }^{25}$

Para asegurar el cumplimiento de la ley y con ello reducir el número de vagos en la ciudad, la misma ley de $\mathbf{2 8}$ de enero de 1845 estipuló que los alcaldes y/o auxiliares de cuartel, o en su defecto sus ayudantes, tenían la obligación de presentarse ante el tribunal para declarar todo lo que supiera sobre los acusaclos. El lugar de residencia indicado por el acusado era el que determinaría qué alcalde o auxiliar debía presentarse a hacer su declaración. De esta manera, la suerte de cualquier persona que llegó al tribunal

\footnotetext{
24 Véase $i b i d$, capítulo quinto, artículos $1^{\circ}$ y $2^{\circ}$.

25 Calderón de la Barca, La vida, 1984, p. 66. El vago y el mendigo fue identificado durante el periodo como el "lépero"; una descripción de ellos la podemos encontrar en las obras de Manuel Payno y Guillermo Prieto, veánse: Los bandidos, 1986 , pp. 87-89, y Memorias, 1906 , pp. 228-230.
} 
dependió en parte de los funcionarios de la corporación municipal. Aunque desde luego dependió también del testimonio de otros testigos.

Lo que resulta evidente, para este momento, es que la legislación sobre la vagancia involucró y responsabilizó cada vez más al personal del ayuntamiento. Ahora no sólo debían cuidar de la buena conducta de las personas que vivian en su cuartel, sino que tenian que certificar la buena o mala conducta de los acusados que llegaban al tribunal. Un año después, en el mes de marzo, Mucio Barquera, presidente de la Asamblea Departamental, dio a conocer el decreto en el que se señalaba que un regidor, nombrado por el ayuntamiento, seria el único juez de vagos (artículo $1^{\circ}$ ). Por otra parte, este documento establecía que la información de los juicios debería "indispensablemente comprender un certificado del dueño de taller público en que trabaje el artesano", y que en el caso de que éste trabajara en su casa, el certificado lo debía extender el alcalde auxiliar del barrio en que habitara. Para las personas que no se dedicaran al trabajo artesanal, se indicó que el auxiliar debía extender un certificado de buena conducta (artículo $8^{\circ}$ ).

Con el fin de hacer efectivo el cumplimiento de la ley de 1845 y del decreto de 1846, se estableció en el artículo noveno de este último que "la falsedad en los certificados o declaraciones de los testigos" sería castigada con la cárcel o el trabajo en obras públicas. ${ }^{26}$

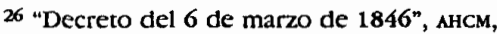
vol. 4779, exp. 334.
Ese mismo año, la prefectura del Distrito excitó a los miembros del ayuntamiento de la capital

encargándoles que por sí mismos en sus respectivos cuarteles, y por medio de sus auxiliares y demás agentes de policía, procuren de toda preferencia la persecución y aprehensión de los vagos, que por desgracia abundan en esta capital; la prefectura, según decía el documento, esperaba la mayor eficacia de los señores capitulares, su cooperación personal y [la] de todos sus agentes, de cuyos buenos y felices resultados tendrán motivo para congratularse, manteniendo con esta benéfica medida la paz de la capital, desterrando de ella el germen de la inseguridad $y$ desmoralizacion. ${ }^{27}$

\section{LOS ACUSADOS DE VAGANCIA}

\section{ANTE EL Tribunal de VAgos}

Prácticamente durante casi todo el siglo XIx, el Tribunal de Vagos se encargó de la calificación de las personas acusadas de vagancia. Hasta antes de 1845, efectuó los juicios y ejecutó la sentencia de los detenidos, pero después de ese año únicamente llevó las averiguaciones y emitió sus dictámenes turnándolos al prefecto político para que diera el fallo final y ejecutara las sentencias. En el periodo comprendido entre 1828 y 1850 , muchos individuos fueron detenidos. No

27 "Excitación de la Prefectura para que los tres capitulares con actividad y empeño persigan a los [ragos] de esta ciudad", $\mathrm{HHCM}$, Vagos, vol. 4782, exp. 404, 16 de abril de 1846 (las cursivas son mías). 


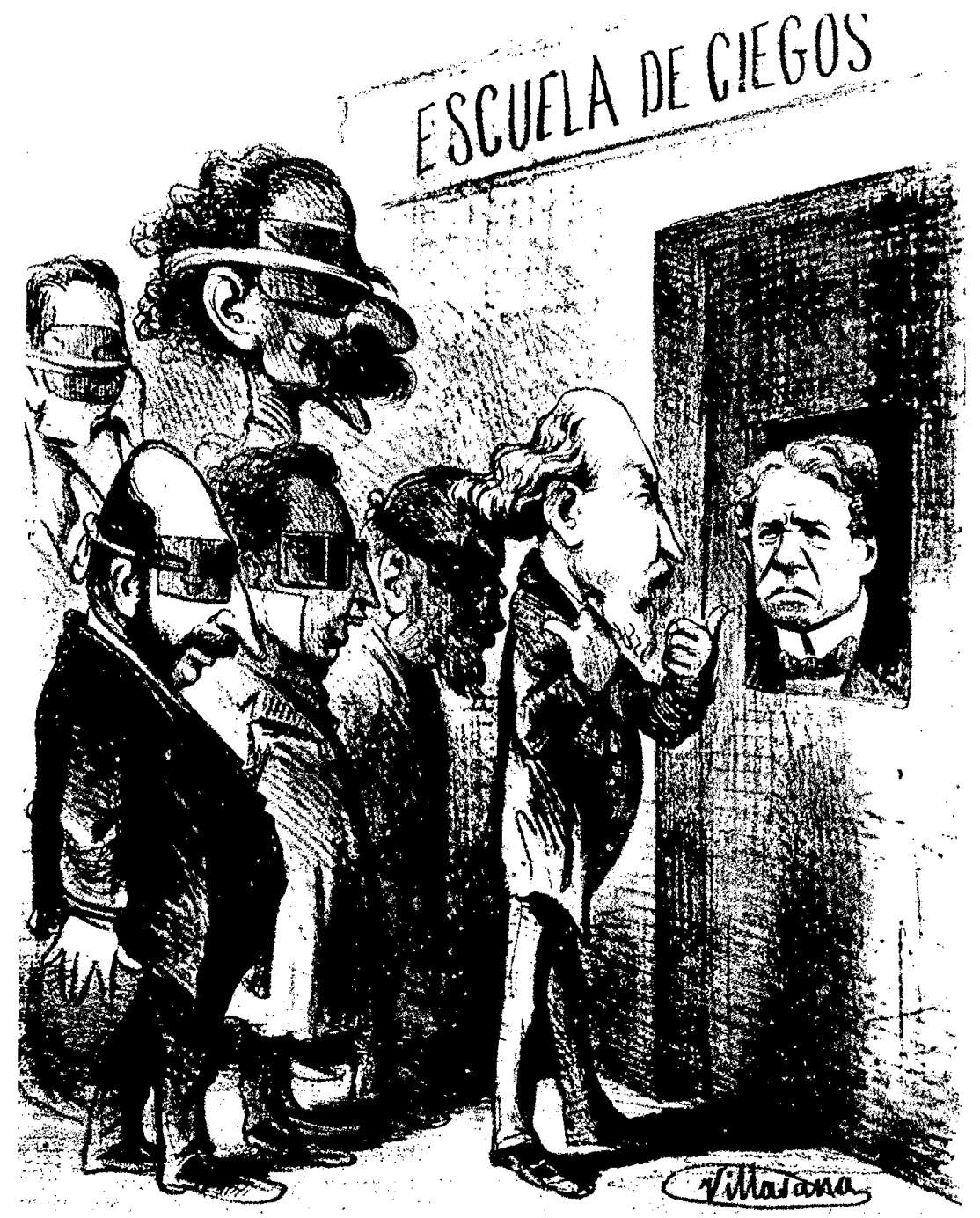

- EL Pueblo al saber los adekantos de esta escuela, enoria a estos Señores para ver si aprenden algo.

- Todos nuestros esfuerzos surian infructuosos, porque adema's de cregos son sordo-mudos. 
Cuadro 1

Grupos de edad de las personas

juzgadas por el Tribunal de Vagos 30

(1828-1850), $534=100 \%$

$\begin{array}{cccccc}\text { Edad } & \text { Cantidad } & \text { Edad } & \text { Cantidad } & \text { Edad } & \text { Cantidad } \\ 5 \text { a } 9 & 1 & \text { 25 a 29 } & 104 & 45 \text { a } 49 & 21 \\ 10 \text { a 14 } & 16 & 30 \text { a } 34 & 55 & 50 \text { a } 54 & 10 \\ 15 \text { a 19 } & 110 & 35 \text { a } 39 & 32 & 55 \text { a } 59 & 8 \\ 20 \text { a } 24 & 156 & 40 \text { a } 44 & 19 & 60 \text { a } 64 & 2\end{array}$

obstante, en el Archivo Histórico de la Ciudad de México sólo se encuentran las sumarias de 576 personas. ${ }^{28}$

Resulta importante apuntar que la información obtenida de estas sumarias se concentra sobre todo en los años $1828,1831,1835,1841$ y 1845 a 1850. La revisión de éstas permite valorar diversos aspectos, tanto del funcionamiento del propio tribunal y de la participación de los funcionarios del ayuntamiento como sobre las personas a las que se les siguió juicio. ${ }^{29}$

\begin{abstract}
${ }^{28}$ En los documentos contenidos en los doce volúmenes relativos a los vagos, que comprenden el periodo de 1828 a 1850 , aparecen listas de un sinnúmero de personas que llegaron al tribunal (de ellas se infiere una mayor actividad en el mismo $y$, por ende, la persistencia de la campaña contra los vagos), desafortunadamente no se encuentran todas las sumarias. Véase, AHCM, Vagos, vol. $4151-4156$ y $4778-4783$.

29 Toda la información que presento a continuación es el resultado de un primer análisis de la base de datos que formé a partir de la revisión de las 576 sumarias contra vagos, que se encuentran en AHCM. Los datos consignados en cada una de ellas son: los generales del acusado (nombre, edad, origen, dirección, oficio u ocupación, estado civil), el delito, la declaración del acusado y la parte acusadora, los generales de los testigos (que casi siempre son los mismos que los del acusado) y su declaración, la sentencia o veredicto del juez del tribunal, el resultado de la apelación en caso de haberla y documentos
\end{abstract}

En primer término, es importante señalar que las mujeres quedaron excluidas de los trabajos del tribunal. En el tiempo que éste funcionó, y quizá porque en la propia legislación contra vagos no se indicó nada en torno al sexo femenino, ninguna de ellas fue acusada de vagancia. Lo que de ninguna manera quiere decir que ésta, tal como se entendía en ese periodo, fuera privativa del sexo masculino.

De las 576 personas sobre las que las sumarias proporcionan información, $83.8 \%$ llegó al tribunal acusado sólo de vagancia; otros, aclemás de esta acusación, fueron turnados por ebriedad, juego, riña y robo; en términos porcentuales, éstos constituyeron 14.4\%. Los restantes (1.8\%), únicamente fueron cosignados como ebrios, jugadores y por riña sin que a estas acusaciones les acompañara la de "vago". De acuerdo con la información disponible, una gran parte de los dete. nidos fluctuaba entre los 15 y 29 años de edad. El cuadro 1 muestra la distribución de los detenidos por grupos de edad.

diversos como constancias de trabajo y/o buen comportamiento.

${ }^{30}$ No llegaron personas mayores de 60 años 
Cerca de $70 \%$ tenía de 15 a 29 años al momento de prestar su declaración ante el juez del tribunal. Esta información es importante porque indica que un buen número de los detenidos se encontraba en edad de trabajar; individuos que supongo carecían de empleo, pues la mayoría indicó tener oficio o actividad. Alejandra Moreno Toscano señala que durante la primera mitad del siglo $\mathrm{XxX}$, cerca de $59 \%$ de la población de la ciudad de México en edad de trabajar carecía de empleo fijo. ${ }^{31}$

Pocos fueron los que se dijeron sin oficio: del total de casos revisados sólo cuatro indicaron que no lo tenían. El $75.2 \%$ se formó de oficiales o aprendices de actividades artesanales; muchos de éstos indicaron que trabajaban en algún taller o en su casa; en otros casos señalaron que en el momento de ser detenidos no se encontraban traba. jando por "no tener obra", o porque la persona para la que trabajaban no la tenía. ${ }^{32}$ El porcentaje tan alto de artesanos que llegaron al tribunal se explica si consideramos que éstos constituían la mayor parte de la población trabajadora de la ciudad de México, y que el proceso de desintegración de

al tribunal entre 1828 y 1850 . Del total de sumarias revisadas sólo en 43 casos no aparece la edad de los acusados.

31 Moreno, "Los trabajadores", 1980, p. 312.

32 Por ejemplo Antonio Medina, maestro en sastrería, al presentarse a declarar en el juicio de Antonio Arias (oficial del mismo ramo), declaró que "hace cosa de un mes que no le da quehacer, por haberse escaseado [el trabajo], pero que le advirtió que lo ocuparía luego que hubiera obra". Véase el juicio contra Antonio Arias en octubre de 1845, AHCM, Vagos, vol. 4156, exp. 260. los gremios (acompañado de una participación cada vez mayor de los comerciantes en las actividades manufactureras), así como la importación de manufacturas, sobre todo de textiles, los hacía más vulnerables.

Durante el periodo del que me ocupo, los artesanos que con mayor frecuencia fueron acusados de vagan. cia y presentados al tribunal fueron, en orden descendente, zapateros, tejedores, sastres y carpinteros (estos oficios concentraban al mayor número de los artesanos de la ciudad). Del total de artesanos a los que se les siguió causa, más de la mitad presentó por lo menos un testigo dedicado también a actividades de tipo artesanal: casi todos los testigos de éstos declararon ser maestros o propietarios de talleres públicos o de "rinconeras". A partir del decreto de 1845, cuando la legislación estableció que las causas seguidas debian contener "indispensablemente" un certificado, un buen número de los testigos que prestaron declaración en favor de los artesanos cumplió con el requisito; los certificados expedidos eran del siguiente tenor:

El C. Santos Ramírez, maestro profesor en el arte de herrería, con taller público en la calle de las Moras. Certifico: que Feliciano Juárez, oficial en el arte de mi profesión, ha trabajado por mucho tiempo en mi taller: ${ }^{33}$

El resto de las personas que llega-

33 Véase la causa seguida contra Feliciano Juárez, AHCM, Vagos, vol. 4782, exp. 399, marzo de 1846. 
ron al tribunal, $24,8 \%$ indicó también tener ocupación: se desempeñaban como albañil, comerciante o vendedor, en las labores de la tierra y como sirviente, cargador, aguador o tocinero.

Del total de individuos enjuiciados, $50 \%$ eran solteros; $46 \%$ casados y sólo $4 \%$ viudos $^{34}$ - las edades de ellos inciden desde luego en las características de esta distribución. Estos porcentajes indican que el desempleo abarcó sin excepción a solteros y casados.

Un poco más de la mitad de los acusados $(53.8 \%)$ eran de la ciudad de México, en tanto que el $46.2 \%$ restante procedía fundamentalmente de zonas que actualmente comprenden los estados de México, Puebla, Hidalgo, Guanajuato, Querétaro y el Distrito Federal. Estos lugares reunían por sí solos al $82.3 \%$ de migrantes, en tanto que el $17.7 \%$ lo formaban personas originarias de Jalisco, Michoacán, San Luis Potosí, Morelos, Zacatecas y Oaxaca, entre otros. El $26.7 \%$ venía de lo que hoy es el estado de México, el 13.1\% del Distrito Federal, el $12.7 \%$ de Puebla, $10.3 \%$ de Hidalgo y Guanajuato y $9.2 \%$ de Querétaro. ${ }^{35}$ Como puede observarse, hay una mínima diferencia entre los detenidos que eran originarios de la ciudad y los que no lo eran; si partimos de la idea que he venido asumiendo, de que las personas que comparecieron ante el tribunal eran en buena parte desempleados o subempleados, esto bien puede indi-

${ }^{3 i}$ De las 576 sumarias, únicamente en 30 no se indica el estado civil del acusado.

35 Sólo cinco extranjeros comparecieron ante el tribunal durante el periodo de estudio. car que la oferta de trabajo de la capital no alcanzaba a cubrir la demanda de trabajo de su población, y menos aún la de aquellos que se trasladaban a ésta en busca de mejor destino. Esta afirmación cobra mayor sentido a partir del análisis de la sentencia $\mathrm{y}$, más tarde, del dictamen emitido por el Tribunal de Vagos.

En el periodo de estudio, fueron absueltos y/o liberados más del 67\%. Aproximadamente al $8 \%$ se le dictaminó como "no vago", se le puso a disposición del prefecto (de acuerdo con la ley de 1845) y con toda seguridad se le liberó como lo recomendaba el tribunal; cerca del $10 \%$ fue liberado y puesto en un taller para que aprendiera un oficio, quedando bajo la responsabilidad del maestro o dueño del taller. En suma, más del $85 \%$ de los detenidos no cubrierón los requisitos para ser calificados de vagos y, por lo mismo, no sufrieron los destinos señalados por la ley. De esta manera, pocas fueron las personas que, como resultado de ser acusados de vagancia, pasaron al servicio de las armas, al de la marina o a la cárcel.

En 1833 el ministro de Relaciones denunció

la facilidad con que se asegura que [en el Tribunal de Vagos] son absueltos los vagos, la mayor con que se dice que acreditan ocupación los que no la tienen, la ligereza con que son creídos. ${ }^{36}$

Sin embargo no era así, ya que

36 "Circular del 20 de agosto de 1833", citada por Arrom, "Vagos", 1988, p. 86. 
los acusados permanecían en la cárcel hasta el momento del fallo; después de su declaración y de forma inde. pendiente el juez del tribunal escuchaba las declaraciones de los testigos que eran citados por el propio tribunal. En todo caso se puede atribuir a la legislación contra la vagancia, $y$ no al tribunal, que la mayor parte de los detenidos fueran liberados, o se utilizara a éste para fines distintos de los encomendados por la ley, ${ }^{37}$ ya que el problema de fondo, la falta de empleo, no podía resolverse sólo mediante disposiciones legales, por más que se buscara perfeccionarlas, como se hizo años después.

Se podría pensar, tal como lo señaló el ministro de Relaciones, que la libe. ración de una gran parte de los detenidos era provocada por el descuido o la indulgencia de quienes estuvieron a cargo del tribunal. Sin embargo, la lectura de las declaraciones de los acusados y sus testigos indica que las personas que llegaron al tribunal eran liberadas porque demostraban (aunque sólo fuese por el testimonio de terceros) tener alguna ocupación u oficio, aun cuando incurrieran en el juego o en alguna otra actividad prohibida por la legislación en la materia. De aquí se desprende que en realidad el tribunal actuó en defensa de los acusados que no tenían empleo, que no de los va-

37 En algunas ocasiones el propio tribunal fue utilizado como vía de escarmiento para los hijos desobedientes, o para el esposo golpeador, infiel o desobligado; pero una vez que se celebraba el juicio, los padres o esposas decidían que con que hubieran llegado al tribunal el castigo era suficiente, $y$ entonces declaraban en su favor. gos. Por otro lado, hay que recordar que gran parte de los individuos lle. vados al tribunal eran artesanos y que éstos tenian un ritmo de trabajo en que trabajo y ocio se entremezclaban -como indica E. P. Thompson-, tanto en el caso del campesino como en el del artesano independiente, de tal forma

que la irregularidad de días y semanas de trabajo se insertaba, hasta las primeras décadas del siglo XIX [y quizá todavía más adelante para el caso mexicanol, dentro de la más amplia irregularidad del año de trabajo, salpicada por sus tradicionales fiestas y ferias, ${ }^{38}$

pues el que un artesano se mantuviera ocupado permanentemente no dependía sólo de su voluntad sino de un sinnúmero de circunstancias que lo trascendían. 39

Si bien es cierto que la legislación, por sus características y ambigüedad, daba lugar a diversas interpretaciones que hacía que se detuviera a personas sospechosas de vagancia, ${ }^{40}$ lo es más 266.

38 Thompson, "Tiempo", 1979, pp. 245 y

39 En el caso de los tejedores, como indica Salvucci, "los periodos de trabajo iban seguidos por periodos de ocio" debido a la reducción de la demanda y a los pocos ingresos que percibían y que les hacían abandonar sus telares para buscar fuentes alternativas. Salvucci, Textiles, 1992, pp. 30-31.

40 En julio de 1831 , la madre del zapatero Jose Trinidad Pérez, acusado de incontinencia y vagancia, fue llamada a declarar, después de alegar que su hijo se dedicaba a su oficio-to que corroboraron otros testigos-; dijo que a éste se le acusaba de ser vago cuando "ni los señores jueces saben lo que es [un] vago", АнСм, Vagos, vol. 4153, exp. 107. 
que muchas de ellas demostraron, en el momento de la averiguación, no ser "vagos" o "malentretenidos". En ese sentido, abundan los testimonios y declaraciones de acusados y testigos que señalan que los detenidos habían trabajado o trabajaban en tal o cual taller, en su casa o para alguna persona. Asimismo, aparecen las declaraciones de los alcaldes de cuartel y de sus ayudantes (con mayor frecuencia a partir de 1845), que dan cuenta del lugar de residencia de los acusados, de sus costumbres y de la actividad que permanentemente o de forma temporal desempeñaban. Por otra parte, abundan también en las sumarias (sobre todo en las de los últimos años del periodo) los certificados o constancias de trabajo.

Una constante de todo el periodo de estudio fueron las quejas por falta de empleo; los siguientes casos sirven para ilustrar el problema. En 1831, por ejemplo, el sastre Juan de Dios García declaró ante el tribunal que

trabaja en su casa, y cuando falta qué hacer lo verifica en el obrador público con su maestro don Ventura [...] y con don Matiano Ordóñez en la calle del Cochero al frente de la casa donde cogen prendas.

Este último fue llamado a declarar en el juicio contra García, y después de reconocerlo, indicó que durante seis años había sido su oficial. Los otros testigos declararon que se le veía trabajar en diversos talleres. ${ }^{41}$ En

\$1 Causa seguida contra Juan de Dios García, ese mismo año Luis Hunda, acusado de vagancia, dijo en su declaración que como su maestro no tenía trabajo que darle, expresó al gobernador su deseo de trabajar y le pidió que lo mandara al Hospicio de Pobres. ${ }^{42}$ Casi veinte años después, en 1850 , el sastre Manuel Hernández declaró que había trabajado en el taller de su maestro Simón, pero que en ese momento no se dedicaba a su oficio por no encontrar lugar dónde ejercerlo. ${ }^{43}$

Declaraciones como éstas las encontramos a lo largo del periodo cle estudio. Son tan frecuentes que constituyen, en resumen, la evidencia que nos permite concluir que una parte considerable de los detenidos no eran sino personas que carecían de empleo permanente, y que la falta de éste los llevaba en algunos casos a ocuparse en actividades diferentes a las de su of cio. Por otro lado, hay que tomar en cuenta que la legislación sobre vagos, que ante todo tenía como objetivos el control de éstos, su "regeneración" o eliminación, reguló también el uso del tiempo libre de la población capitalina (en particular el de la gente pobre), por lo que no debe extrañar el hecho de que algunos de los que comparecieron ante el tribunal fueran detenidos jugando naipes o rayuela sin que por ello carecieran de un oficio $y / 0$ trabajo, por más inestable o temporal que éste fuera. En el México independiente, tal

oficial de sastrería en 1831, АHCM, Vagos, vol. 4152, exp. 58.

42 Ibid., exp. 73.

43 Véase causa seguida a Manuel Hernández en julio de 1850, АнСм, Vagos, vol. 4783, exp. 443. 


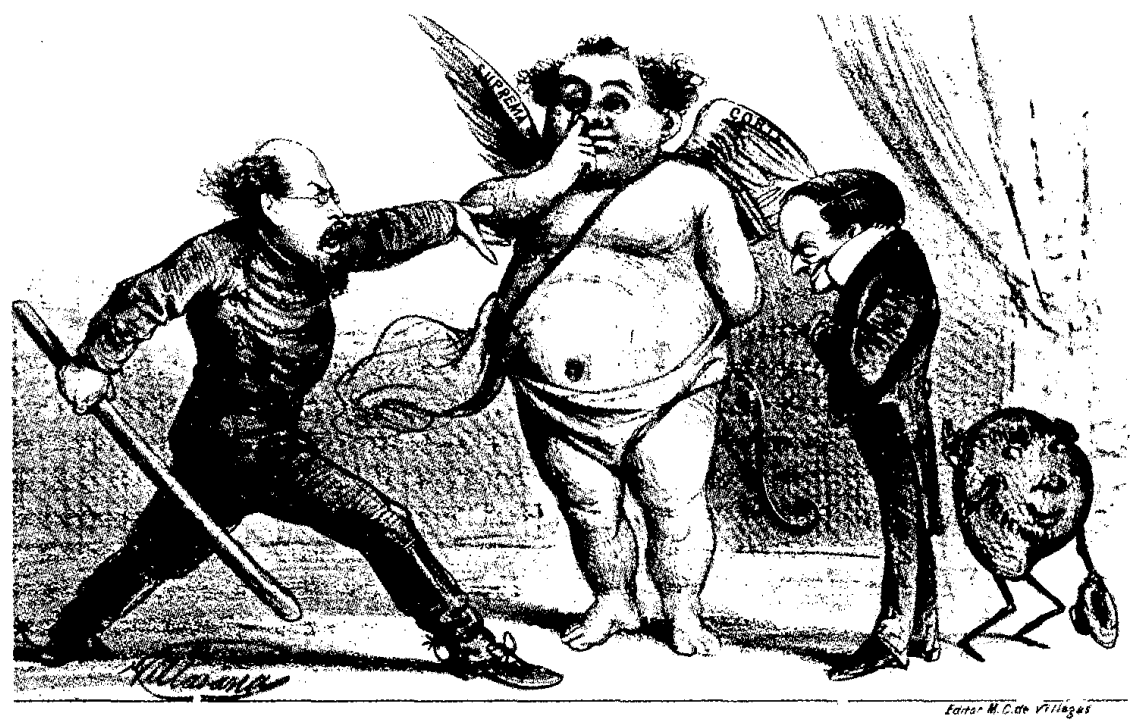

¿ Porqué dejasie. crecer mi amor,.... si esquivo estaba lu corazon? ? ...

como había sucedido en otros centros urbanos allende los mares, la legislación contra la vagancia se encontró vinculada a la eliminación de ciertas costumbres o conductas indeseables. E. P. Thompson apuntó para el caso inglés, por ejemplo, que

el largo coro del amanecer de los moralistas es el preludio de un ataque bastante vivo a las costumbres, deportes y fiestas populares que se realizó en los últimos años del siglo xvIIl y primeros del $x i x .^{44}$

Finalmente, es necesario apuntar que las disposiciones y leyes contra

44 Thompson, "Tiempo", 1979, p. 276. la vagancia no fueron otra cosa sino intentos poco afortunados que no lograron disminuir, de hecho, a la población que tanto preocupó a las autoridades y a la gente "decente" de la capital. No obstante, esta legislación y los diversos intentos por aplicarla muestran la clara intención de las autoridades de imponer a una buena parte de la población capitalina "el amor al trabajo, a la instrucción y a las buenas costumbres".

\section{Bibliografía}

-Arrom, Silvia, "Vagos y mendigos en la legislación mexicana. 1745-1845", en Memorta del IV Congreso de Historia del Derecho Mexicano, UNaM, México, 1988, vol. I, pp. 71-87. 
-Calderón de la Barca, Francis, La vida en México, Editorial Porrúa, México, 1984.

-Di Tella, Torcuato, "Las clases peligrosas a comienzos del siglo xIX en México", Desarrollo Económico, núm, 48, 1977, pp. 481-524.

-Dublán, Manuel y José María Lozano, Legislación mexicana o Colección com pleta..., Imprenta de Comercio, México, 1876 , vol. II.

-Martin, Norman, "Pobres, mendigos y vagabundos en la Nueva España, 1702. 1766", Estudios de Historia Novobispana, México, 1985, vol. III, pp. 99-126.

-Moreno, Alejandia, "Los trabajadores y el proyecto de industrialización, 18101867", en Enrique Florescano et al., La clase obrera en la bistoria de México Siglo XXI Editores, México, vol. I.

-Payno, Manuel, Los bandidos de Rio Frio, Editorial Porrúa, México, 1986.

-Prieto, Guillermo, Memorias de mis tiempos, Libiería de Ch. Bouret, México, 1906.
-Salvucci, Richard, Textiles y captialismo en México, una bistoria económica de los obrajes, 1539-1840, Alianza Editorial Mexicana, México, 1992.

-Sewell, William, Work and revolution in France. The language of labor from the Old Regime to 1848 , Cambridge University Press, Nueva York, 1987.

-Thompson, Edward P., "Tiempo, disciplina y capitalismo", en Tradición, re. vuelta y conciencia de clase, Barcelona, Editorial Crítica, 1979, pp. 239-293.

-Van Young, Eric, "Islands in the storm: Quiet cities and violent countrysides in the mexican independence era", Past and Present, núm. 118, febrero de 1988.

, The rich get richer and the poor get skewed: Real wages and popular living standards in late colonial México, Congreso de All-UC Group in Economic History, Huntington Library/Caltech, 1987. 